\title{
PERAN KEPEMIMPINAN, SOFT COMPETENCY, DAN IKLIM ORGANISASI TERHADAP KINERJA KARYAWAN
}

\author{
Lisna Rita Riama Sinaga \\ Program Studi Magister Manajemen Universitas Tarumanagara \\ lisnaritariamasinaga@ymail.com \\ Mukti Rahardjo \\ Program Studi Magister Manajemen Universitas Tarumanagara
}

Masuk : 06-12-2019, revisi : 20-12-2019 diterima untuk diterbitkan : 21-12-2019

\begin{abstract}
The purpose of this research is to study the role of leadership, soft competency, and organizational climate on employee performance. This research method uses quantitative descriptive research. This quantitative descriptive research is used to determine the value of independent variables, either one or more variables (independent) without making comparisons, or connecting with other variables. The sample of this study was taken from 82 employee respondents in the company PT. XYZ. Data analysis techniques used in this study are hypotheses and statistical tests, which consist of validity, reliability, classic assessment tests (normality test, multicollinearity test, heteroscedasticity test, multiple linear regression test), and hypothesis testing methods ( $\mathrm{t}$ test, $\mathrm{F}$ test, analysis of the coefficient of determination (R2), analysis of the coefficient of coordination (R)). The results are: (a) There is a positive role in leadership in employee performance; (B) There is a positive role for soft competency in employee performance; (c) There is a positive role for organizational climate in employee performance; (d) The role of leadership, soft competency, and organizational climate has a positive influence on employee performance, which can overcome the variable increase, employee performance is also positive or increased.
\end{abstract}

Keywords : Leadership; Soft Competency; Organizational Climate; Employee Performance

\begin{abstract}
Abstrak : Tujuan dari penelitian ini adalah untuk mempelajari peran kepemimpinan, kompetensi lunak, dan iklim organisasi terhadap kinerja karyawan. Metode penelitian ini menggunakan penelitian deskriptif kuantitatif. Penelitian deskriptif kuantitatif ini digunakan untuk mengetahui nilai variabel independen, baik satu atau lebih variabel (independen) tanpa membuat perbandingan, atau menghubungkan dengan variabel lain. Sampel penelitian ini diambil dari 82 responden karyawan di perusahaan PT. XYZ. Teknik analisis data yang digunakan dalam penelitian ini adalah hipotesis dan uji statistik, yang terdiri dari validitas, reliabilitas, tes asumsi klasik (uji normalitas, uji multikolinieritas, uji heteroskedastisitas, uji regresi linier berganda), dan metode pengujian hipotesis (uji t, uji $\mathrm{F}$, analisis koefisien determinasi (R2), analisis koefisien koordinasi (R)). Hasilnya adalah: (a) Ada peran positif dalam kepemimpinan dalam kinerja karyawan; (B) Ada peran positif untuk soft competency dalam kinerja karyawan; (c) Ada peran positif untuk iklim organisasi dalam kinerja karyawan; (d) Peran kepemimpinan, soft competency, dan iklim organisasi memiliki pengaruh positif terhadap kinerja karyawan, yang dapat mengatasi peningkatan variabel, kinerja karyawan juga positif atau meningkat.
\end{abstract}

Kata Kunci : Kepemimpinan; Soft Competency; Iklim Organisasi; Kinerja Karyawan 


\section{PENDAHULUAN}

Masalah kinerja tidak terlepas dari proses, hasil dan daya guna, dalam hal ini kinerja atau prestasi kerja merupakan hasil kerja secara kualitas dan kuantitas yang dicapai oleh seorang pegawai dalam melaksanakan tugasnya sesuai dengan tanggung jawab yang diberikan kepadanya. Kinerja karyawan yang baik secara langsung akan mempengaruhi kinerja perusahaan, dan untuk memperbaiki kinerja karyawan merupakan suatu pekerjaan yang memakan waktu dan proses yang panjang. Selain dengan meningkatkan pengawasan dan pembinaan, juga dilakukan penilaian terhadap tingkat keberhasilan kerja yang dilakukan oleh para karyawannya. Penilaian kinerja juga bermanfaat sebagai tolok ukur yang dapat digunakan untuk memperbaiki kinerja karyawan yang bersangkutan. Tujuan dari penelitian ini adalah untuk mengetahui peran kepemimpinan, soft competency, dan iklim organisasi terhadap kinerja karyawan.

\section{TUJUAN PENELITIAN}

1. Mengetahui apakah kepemimpinan mempunyai peran terhadap kinerja karyawan,

2. Mengetahui apakah soft competency mempunyai peran terhadap kinerja karyawan,

3. Mengetahui apakah iklim organisasi mempunyai peran terhadap kinerja karyawan,

4. Mengetahui apakah kepemimpinan, soft competency, dan iklim organisasi secara simultan mempunyai peran terhadap kinerja karyawan.

\section{TELAAH PUSTAKA}

Koopmans (2014) mendefinisikan kinerja sebagai pola perilaku dan tindakan dari para karyawan yang relevan dengan tujuan organisasi. Kinerja ini lebih menekankan pada pola perilaku dan tindakan karyawan dibandingkan dengan hasil dari perilaku itu sendiri. Hal ini berisi perilaku yang berada dibawah kontrol dari individu itu sendiri, kecuali perilaku tersebut dipengaruhi oleh lingkungannya.

Menurut Koopsman (2014), terdapat tiga jenis dari kinerja yaitu : (1) Task performance, (2) Contextual performance, dan (3) Contraproductive work behavior.

Berdasarkan hipotesis tersebut, maka peneliti mengemukakan definisi operasionalnya sebagai berikut :

1. Peran adalah proses dinamis kedudukan (status). Apabila seseorang melaksanakan hak dan kewajibannya sesuai dengan kedudukannya, dia menjalankan suatu peranan. Perbedaan antara kedudukan dengan peranan adalah untuk kepentingan ilmu pengetahuan. Keduanya tidak dapat dipisah-pisahkan karena yang satu tergantung pada yang lain dan sebaliknya. (Soerjono Soekanto, 2009).

2. Kepemimpinan adalah suatu proses mempengaruhi orang lain untuk memahami dan setuju dengan apa yang perlu dilakukan dan bagaimana tugas itu dilakukan secara efektif, serta proses untuk memfasilitasi upaya individu dan kolektif untuk mencapai tujuan bersama. (Yulk, 2005).

3. Soft Competency menggambarkan bagaimana seseorang diharapkan berperilaku agar dapat melaksanakan pekerjaannya dengan baik. (Hutapea, et al (2008)).

4. Iklim organisasi merupakan efek persepsi subjektif terhadap sistem formal, gaya informal manajer, dan faktor-faktor lingkungan lain yang berpengaruh pada sikap, keyakinan, nilai, dan motivasi dari orang-orang yang bekerja pada suatu perusahaan tertentu. (George H. Litwin and Robert A. Stringer, Jr. (1968: 5))

5. Kinerja adalah perilaku dan tindakan individu yang sesuai dengan tujuan dari organisasi (Koopmans, 2014)

\section{METODOLOGI PENELITIAN}

Populasi dan Metode Pengambilan Sampel. Populasi dalam penelitian ini adalah karyawan PT. XYZ. Ukuran sampel yang digunakan dalam penelitian ini adalah 82 orang. 
Metode pengambilan sampel yang digunakan adalah penelitian deskriptif kuantitatif, yang bertujuan untuk mengetahui nilai variabel mandiri, baik satu variabel atau lebih (independen) tanpa membuat perbandingan, atau menghubungkan dengan variabel yang lain.

Variabel dan Pengukuran. Variabel dalam penelitian ini dibagi menjadi dua, yaitu varibel bebas dan variabel terikat. Variabel bebas adala variabel yang nilainya tidak dipengaruhi variabel yang lain, sedangkan variabel terikat merupakan variabel yang nilainya dipengaruhi oleh variabel bebas. Variabel bebas dalam penelitian ini adalah Kepemimpinan $\left(\mathrm{X}_{1}\right)$, Soft Competency $\left(\mathrm{X}_{2}\right)$ dan Iklim Organisasi $\left(\mathrm{X}_{3}\right)$. Sedangkan variabel terikat pada penelitian ini adalah Kinerja Karyawan (Y).

Metode Analisis Data. Teknik analisis data yang digunakan dalam penelitian ini adalah hipotesis statistik dan pengujian, yang dimana terdiri dari uji validitas, reliabilitas, uji asumsi klasik (uji normalitas, uji multikolinearitas, uji heteroskedastisitas, Uji Regresi Linier Berganda), dan metode pengujian hipotesis (uji T, uji F, Analisis Koefisien Determinasi $\left(\mathrm{R}^{2}\right)$, Analisis Koefisien Korelasi (R))

\section{ANALISIS DAN BAHASAN TEMUAN}

Tabel 1

Hasil Uji F

\begin{tabular}{|l|r|r|r|r|r|}
\hline Model & Sum of Squares & df & Mean Square & F & Sig. \\
\hline Regression & 283,746 & 3 & 94,582 & 46,388 &, $000^{\mathrm{b}}$ \\
Residual & 159,035 & 78 & 2,039 & & \\
Total & 442,780 & 81 & & & \\
\hline
\end{tabular}

Berdasarkan data tabel di atas, diperoleh tingkat signifikansi sebesar 0,000 yang menunjukan bahwa angka tersebut lebih kecil dari 0,05. Hal ini dapat kita simpulkan bahwa $\mathrm{H}_{0}$ ditolak maka dapat disimpulkan bahwa terdapat pengaruh yang signifikan dari variabel kepemimpinan, soft competency, dan iklim organisasi terhadap kinerja karyawan.

Tabel 2

\begin{tabular}{|c|c|c|c|c|c|c|c|}
\hline & & & Hasil Uji t & & & & \\
\hline \multirow[t]{2}{*}{ Model } & \multicolumn{2}{|c|}{$\begin{array}{c}\text { Unstandardized } \\
\text { Coefficients }\end{array}$} & \multirow{2}{*}{$\begin{array}{c}\text { Standardized } \\
\text { Coefficients }\end{array}$} & \multirow[t]{2}{*}{$\mathrm{t}$} & \multirow[t]{2}{*}{ Sig. } & \multicolumn{2}{|c|}{ Collinearity Statistics } \\
\hline & B & Std. Error & & & & Tolerance & VIF \\
\hline \multirow[t]{4}{*}{ (Constant) } & 4,765 & 1,499 & & 3,178 & 002 & & \\
\hline & , 181 & ,075 &, 231 & 2,421 & ,018 &, 508 & 1,970 \\
\hline & ,238 & 066 & ,294 & 3,592 & ,001 & ,689 & 1,452 \\
\hline & 202 & 051 & 421 & 3,954 &, 000 & 407 & 2,459 \\
\hline
\end{tabular}

Berdasarkan tabel di atas, diperoleh variabel kepemimpinan memiliki nilai signifikansi sebesar 0,018. Nilai signifikansi tersebut lebih kecil dari 0,05, dimana hal ini menunjukkan bahwa terdapat pengaruh kepemimpinan terhadap kinerja karyawan, artinya $\mathrm{Ha}_{1}$ diterima. Variabel soft competency memiliki nilai signifikansi sebesar 0,001. Nilai signifikansi tersebut lebih kecil dari 0,05, dimana hal ini menunjukkan bahwa terdapat pengaruh soft competency terhadap kinerja karyawan, artinya $\mathrm{Ha}_{2}$ diterima. Variabel iklim organisasi memiliki nilai signifikansi sebesar 0,000. Nilai signifikansi tersebut lebih kecil dari 0,05, dimana hal ini menunjukkan bahwa terdapat peran iklim organisasi terhadap kinerja karyawan, artinya $\mathrm{Ha}_{3}$ diterima. 
Tabel 3

Hasil Uji Koefisien Determinasi $\left(\mathbf{R}^{2}\right)$

\begin{tabular}{|l|r|r|r|r|r|}
\hline Model & $R$ & $R$ Square & $\begin{array}{c}\text { Adjusted R } \\
\text { Square }\end{array}$ & $\begin{array}{r}\text { Std. Error of } \\
\text { the Estimate }\end{array}$ & Durbin-Watson \\
\hline 1 &, $801^{a}$ &, 641 &, 627 & 1,42790 & 1,824 \\
\hline
\end{tabular}

a. Predictors: (Constant), IO, SC, KP

b. Dependent Variable: KK

Berdasarkan tabel diatas dapat dilihat nilai koefisien determinasi adalah sebesar 0,627. Berdasarkan hasil tersebut dapat disimpulkan bahwa sebesar 62,7\% variabel dependennya (kinerja karyawan) dapat dijelaskan oleh variabel independen yaitu kepemimpinan, soft competency, dan iklim organisasi sedangkan sisanya yaitu sebesar 37,3\% (100\%-62.7\%) dijelaskan oleh variabel-variabel lainnya yang tidak diungkapkan dalam penelitian ini.

Tabel 4

Hasil Uji Koefisien Korelasi (R)

\begin{tabular}{|l|r|r|r|r|r|}
\hline Model & $\mathbf{R}$ & R Square & Adjusted R Square & $\begin{array}{c}\text { Std. Error of the } \\
\text { Estimate }\end{array}$ & $\begin{array}{r}\text { Durbin- } \\
\text { Watson }\end{array}$ \\
\hline 1 &, $\mathbf{8 0 1}^{\mathrm{a}}$ &, 641 &, 627 & 1,42790 & 1,824 \\
\hline
\end{tabular}

a. Predictors: (Constant), IO, SC, KP

b. Dependent Variable: KK

Berdasarkan tabel diatas, diperoleh nilai korelasi (R) sebesar 0,801. Berdasarkan hasil tersebut dapat disimpulkan bahwa hubungan antara variable kepemimpinan, soft competency, dan iklim organisasi terhadap kinerja karyawan adalah sangat kuat. Hal tersebut dapat dilihat dari nilai $\mathrm{R}$ yang semakin mendekati satu.

Tabel 5

Hasil Uji Hipotesis

\begin{tabular}{|l|c|c|c|}
\hline \multicolumn{1}{|c|}{ Hipotesis } & \multicolumn{1}{|c|}{$\begin{array}{c}\text { Nilai } \\
\text { Signifikansi }\end{array}$} & $\begin{array}{c}\text { Hasil } \\
\text { Pengujian }\end{array}$ & $\begin{array}{c}\text { Hipotesis } \\
\text { Diterima/Ditolak }\end{array}$ \\
\hline $\begin{array}{l}\text { Ha1 : Terdapat peran } \\
\text { kepemimpinan } \\
\text { terhadap kinerja } \\
\text { karyawan }\end{array}$ & 0,018 & Sig $<0,05$ & Haterima \\
\hline $\begin{array}{l}\text { Ha2 : Terdapat peran } \\
\text { soft competency } \\
\text { terhadap kinerja } \\
\text { karyawan }\end{array}$ & 0,001 & Sig $<0,05$ & Ha2 diterima \\
\hline $\begin{array}{l}\text { Ha3 : Terdapat peran } \\
\text { iklim organisasi } \\
\text { terhadap kinerja } \\
\text { karyawan }\end{array}$ & 0,000 & Sig $<0,05$ & Ha3 diterima \\
\hline
\end{tabular}

Berdasarkan hasil uji yang telah dilakukan dari hasil jawaban kuesioner yang diisi oleh 82 karyawan di PT.XYZ, didapatkan hasil bahwa Kepemimpinan, soft competency, dan iklim organisasi memberikan pengaruh secara simultan sebesar 0,627 atau $62,7 \%$ yang kemudian sisanya dipengaruhi oleh faktor lain diluar model. 


\section{KESIMPULAN DAN SARAN}

\section{Kesimpulan}

Berdasarkan dari hasil penelitian analisis yang sudah di bahas dalam bab IV, maka dapat disimpulkan sebagai berikut:

1. Terdapat peran positif kepemimpinan terhadap kinerja karyawan.

2. Terdapat peran positif soft competency terhadap kinerja karyawan.

3. Terdapat peran positif iklim organisasi terhadap kinerja karyawan.

4. Peran kepemimpinan, soft competency, dan iklim organisasi memiliki pengaruh positif terhadap kinerja karyawan, kesimpulannya yaitu jika ketiga variabel itu meningkat maka kinerja karyawan juga positif/meningkat.

\section{Saran}

Terkait dengan hasil penelitian diatas, maka peneliti akan memberikan beberapa saran yang sekiranya bisa bermanfaat bagi perusahaan dan bagi peneliti lain, antara lain sebagai berikut:

1. Bagi penelitian selanjutnya, peneliti menyarankan agar memperluas jangkauan pengambilan sampelnya. Hal tersebut bertujuan agar memperkuat dan melengkapi penelitian sebelumnya.

2. Penelitian selanjutnya dapat menggunakan periode penelitian yang lebih panjang yaitu lebih dari 1 bulan agar hasilnya dapat lebih menggambarkan kondisi yang ada dan memberikan hasil yang jauh lebih baik dari penelitian ini.

3. Menambahkan variabel independen lain yang memiliki peranan terhadap kinerja karyawan seperti hard competency, pengembangan karis, disiplin kerja dan lain-lain.

\section{DAFTAR PUSTAKA}

Adiyanti, Siska Ayudia. (2016). Pengaruh Kepemimpinan Transformasional Dan Budaya Organisasi Terhadap Kinerja SDM Di Organisasi Perangkat Daerah (OPD) Kota Sukabumi.

Amstrong, M. (2000). Manajemen Sumber Daya Manusia. Jakarta: Erlangga

Azanita, Cut. (2016). Pengaruh Motivasi Kerja Dan Gaya Kepemimpinan Atasan Terhadap Kinerja Pegawai Melalui Komitmen Organisasi Di Kementerian Hukum Dan HAM Republik Indonesia. Vol 13. No. 1

Basori, Prahiawan, Daenulhay. (2017). Pengaruh Kompetensi Karyawan Dan Lingkungan Kerja Terhadap Kinerja Karyawan Melalui Motivasi Kerja Sebagai Variabel Intervening. Vol. 1 (2). Hal 149-157

Gathmyr, Dewi. (2017). Pengaruh Iklim Organisasi Dan Komitmen Profesi Terhadap Kinerja Perwira Penerbang TNI Angkatan Udara Di Skadron Udara 31 Halim Perdanakusuma Jakarta. Vol. 3. No. 2

Ghozali, Imam. (2007). Aplikasi Analisis Multivariate dengan Program SPSS). Badan Penerbit Universitas Diponegoro, Semarang

Ghozali, Imam. (2009). Aplikasi Analisis Multivariate dengan Program SPSS. Semarang : UNDIP.

Ghozali, Imam. (2011). Aplikasi Analisis Multivariate Dengan Program SPSS. Semarang: Badan Penerbit Universitas Diponegoro.

Jogiyanto Hartono. (2013). Metodologi Penelitian Bisnis: Salah Kaprah dan PengalamanPengalaman, BPFE Yogyakarta, Edisi Keenam, Yogyakarta

Kopmanss. (2014). Measuring individual work performance. Amsterdam, NLD: Institute for health and care research.

Litwin, George H. \& Stringer, Robert A. (1968). Motivation and Organizational Climate. Harvard University.

Nazir, Moh. (2005). Metode Penelitian. Jakarta : Ghalia Indonesia 
Nurnaeni, Umi. (2017). Gambaran Kinerja Dan Keterikatan Kerja Pada Pegawai Pengelola Barang/Jasa Pemerintah. Vol.1. No. 2

Rokhayati, Kambara, Ibrahim. (2017). Pengaruh Soft Skill Dan Perencanaan Karir Terhadap Kinerja Karyawan Dengan Kualitas Pelatihan Sebagai Variabel Moderator. Vol. 1 (2). No. 107-124

Setiawan, Kiki Cahaya. (2015). Pengaruh Iklim Organisasi Terhadap Kinerja Karyawan Level Pelaksana Di Divisi Operasi PT. Pusri Palembang. Vol. 1. Hal 1

Soerjono Soekanto. (2009). Sosiologi Suatu Pengantar. Edisi Baru : Rajawali Pers.Jakarta

Sugiyono. (2002). Metode Penelitian Administrasi. Bandung : CV Alfabeta

Sugiyono. (2003). Metode Penelitian Bisnis. Edisi 1, Bandung: Alfabeta

Sugiyono. (2010). Metode Penelitian Pendidikan Pendekatan Kuantitatif, Kualitatif, dan R\&D. Bandung: Alfabeta

Sugiyono. (2012). Metode Penelitian Kuantitatif Kualitatif dan $R \& D$. Bandung : Alfabeta.

Suliyanto. (2006). Metode Riset Bisnis. Yogyakarta : Andi.

Yukl, Gary A. (2005). Kepemimpinan Dalam Organisasi. Edisi Kelima. Jakarta : PT INDEKS. 